\title{
Invasive Hemodynamic Monitoring in the Postoperative Period of Cardiac Surgery
}

\author{
Desanka Dragosavac, Sebastião Araújo, Maria do Carmo Monteiro Carieli, Renato G. G. Terzi, \\ Sanja Dragosavac, Reinaldo Wilson Vieira
}

Campinas, SP - Brazil

\begin{abstract}
Objective - To assess the hemodynamic profile of cardiac surgery patients with circulatory instability in the early postoperative period (POP).

Methods - Over a two-year period, 306 patients underwent cardiac surgery. Thirty had hemodynamic instability in the early POP and were monitored with the Swan-Ganz catheter. The following parameters were evaluated: cardiac index (CI), systemic and pulmonary vascular resistance, pulmonary shunt, central venous pressure (CVP), pulmonary capillary wedge pressure $(P C W P)$, oxygen delivery and consumption, use of vasoactive drugs and of circulatory support.
\end{abstract}

Results - Twenty patients had low cardiac index (CI), and 10 had normal or high CI. Systemic vascular resistance was decreased in 11 patients. There was no correlation between oxygen delivery $\left(D_{2}\right)$ and consumption $\left(V \mathrm{~V}_{2}\right), p=0.42$, and no correlation between CVP and PCWP, $p=0.065$. Pulmonary vascular resistance was decreased in 15 patients and the pulmonary shunt was increased in 19. Two patients with $\mathrm{CI}<2 \mathrm{~L} / \mathrm{min} / \mathrm{m}^{2}$ received circulatory support.

Conclusion-Patients in the POP of cardiac surgery frequently have a mixed shock due to the systemic inflammatory response syndrome (SIRS). Therefore, invasive hemodynamic monitoring is useful in handling blood volume, choice of vasoactive drugs, and indication for circulatory support.

Key words: cardiac surgery, Swan-Ganz catheter

Faculdade de Ciências Médicas-UNICAMP - Campinas

Mailing address: Desanka Dragosavac - Rua Lopes Trovão, 336/112 - 13090-090

- Campinas, SP

Received on $10 / 28 / 98$

Accepted on $01 / 27 / 99$
In 1945, Leniz Dexter performed the first catheterization of the pulmonary artery to diagnose congenital heart disease $^{1}$. The history of the clinical hemodynamic monitoring began after the publication by Swan and Ganz introducing the use of the balloon catheter for the pulmonary artery, in $1970^{2}$. The use of the Swan-Ganz catheter (SGC) has increased each year throughout the world, despite being an invasive and expensive procedure ${ }^{3}$. In 1975, it was employed in $7.2 \%$ of the patients with acute myocardial infarction (AMI), increasing to $19.9 \%$ in $1984^{4}$.

Since the report by Gore et $\mathrm{al}^{4}$ on the use of the SGC in patients with AMI, where a higher mortality was shown in patients monitored with the SGC as compared with those monitored with the central venous catheter (CVC), there has been great controversy in the literature about the costs and benefits of that type of monitoring ${ }^{5-8}$.

The dispute culminated with the publication of an editorial by Dalen and Bone ${ }^{3}$ asking for the suspension of the monitoring with the SGC until randomized and comparative studies could be performed to better define the risks.

The objective of our study was to analyze, retrospectively, the hemodynamic profile of patients undergo-ing cardiac surgery with circulatory instability in the early postoperative period (POP), discuss our experience and the benefits obtained with the SGC in this category of patients.

\section{Methods}

A retrospective study was performed. We analyzed the medical records of all patients who underwent cardiac surgery and were admitted to the intensive care unit of the HC-UNICAMP, in the years of 1995 and 1996, and who required hemodynamic monitoring with the SGC due to hemodynamic instability in the early POP.

In all patients with instability following cardiac surgery, the first drug used for hemodynamic support was dopamine. Those patients who remained hypotensive (systolic pressure $<90 \mathrm{mmHg}$ ) with $10 \mu \mathrm{g} / \mathrm{kg} / \mathrm{min}$ of dopamine underwent invasive hemodynamic monitoring with the SGC. The need for a second drug (dobutamine, nora- 
drenaline or sodium nitroprusside) or circulatory support was determined only after invasive monitoring.

The following parameters were assessed: cardiac index (CI), pulmonary (PVR) and systemic vascular resistance (SVR), pulmonary shunt, oxygen delivery and consumption, and correlation between central venous pressure (CVP) and pulmonary capillary wedge pressure (PCWP). The use of vasoactive drugs and their indications due to the measurements obtained through monitoring were also evaluated, as was the use of circulatory support in patients with $\mathrm{CI}<2 \mathrm{~L} / \mathrm{min} / \mathrm{m}^{2}$.

The Pearson correlation coefficient was used for the statistical analysis, with a level of significance of $5 \%(\mathrm{p}<0.05)$.

\section{Results}

During 1995 and 1996, 306 patients in the POP of cardiac surgery were admitted to the intensive care unit of the $\mathrm{HC}$ UNICAMP.

Thirty of these patients, with a mean age of $57.72 \pm 14.37$ years, were monitored with the SGC due to hemodynamic instability in the early POP. Twenty-one of these patients were males. Theirtypes of surgery are listed in tableI.

The following hemodynamic measures were obtained:CI20 patients had CI $<3.5 \mathrm{~L} / \mathrm{min} / \mathrm{m}^{2} ; 7$ patientshadCI $>4.1 \mathrm{~L} / \mathrm{min} / \mathrm{m}^{2}$; and 3 patients had values of CI within the acceptable range (3.5-4 $\left.\mathrm{L} / \mathrm{min} / \mathrm{m}^{2}\right)$. Theminimal valuefoundwas $1.35 \mathrm{~L} / \mathrm{min} / \mathrm{m}^{2}$, themaximal was $6.84 \mathrm{~L} / \mathrm{min} / \mathrm{m}^{2}$ and themean was $3.14 \pm 1.36 \mathrm{~L} / \mathrm{min} / \mathrm{m}^{2}$ (fig. 1).

Table I - Diagnosis of patients monitored with the Swan-Ganz catheter
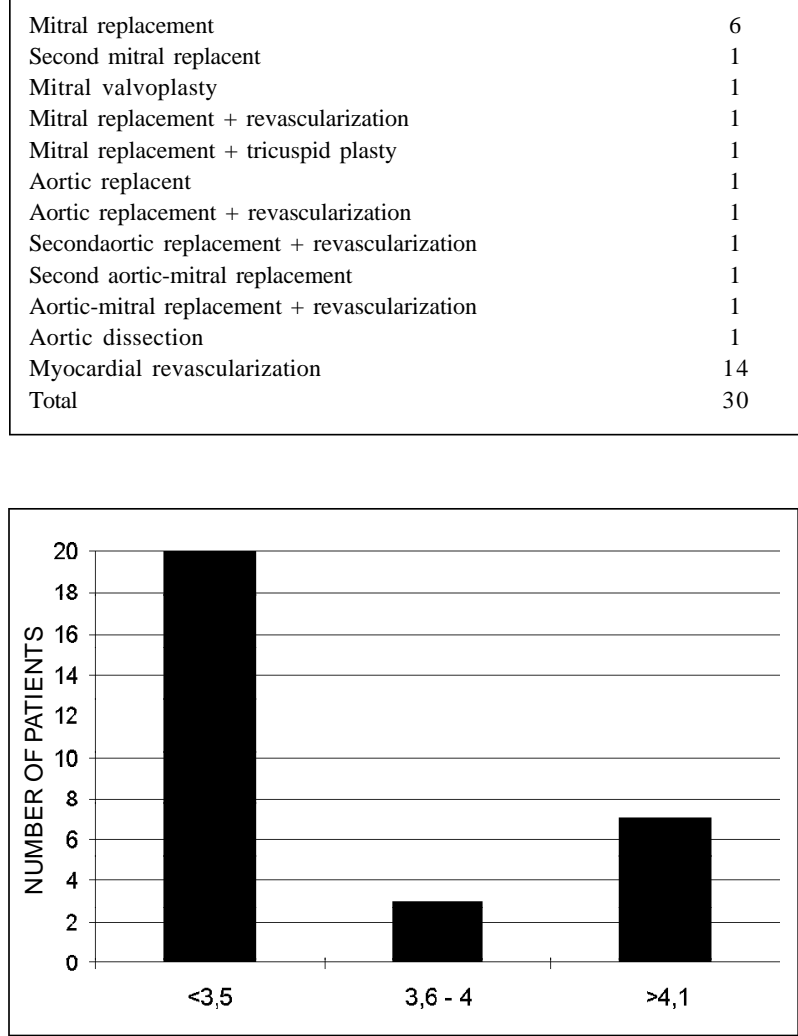

Fig. 1 - Cardiac index CI L/min $/ \mathrm{m}^{2}$. Mean value $3.14 \pm 1.36$; $\min 1.35 ; \max 6.84$.
Ten patients had a normal systemic vascular resistance (SVR); 11 patients had SVR $<800 \mathrm{dyn} / \mathrm{sec} / \mathrm{cm}^{5}$ and 9 patients had SVR $>1201 \mathrm{dyn} / \mathrm{sec} / \mathrm{cm}^{5}$. The minimal value was 312 and the maximal value was $2425 \mathrm{dyn} / \mathrm{sec} / \mathrm{cm}^{5}$ (fig. 2).

In 11 patients, the PVR was normal; in 15 patients, PVR was $<150 \mathrm{dyn} / \mathrm{sec} / \mathrm{cm}^{5}$ and in 4 patients, PVR was $>250 \mathrm{dyn} /$ $\mathrm{sec} / \mathrm{cm}^{5}$ (fig. 3).

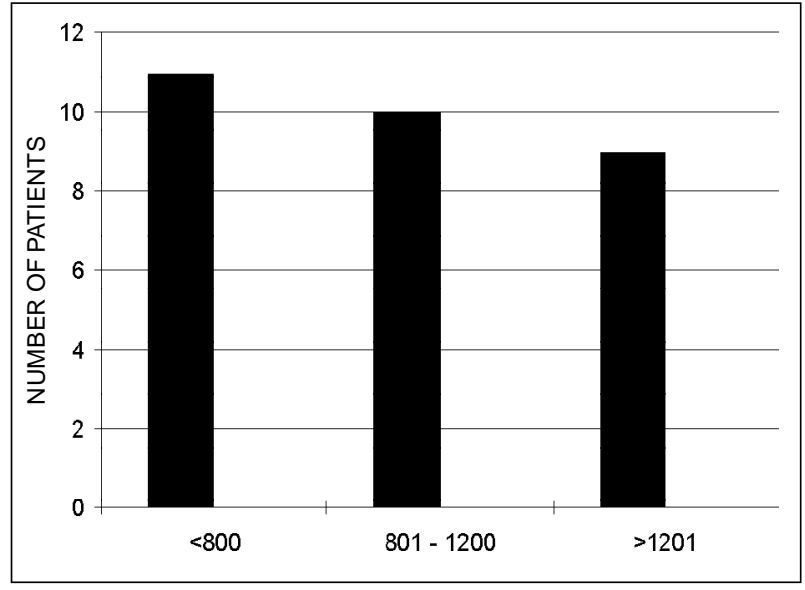

Fig. 2 - Systemic vascular resistency. SVR- dyn $/ \mathrm{s} / \mathrm{cm}^{5}$.

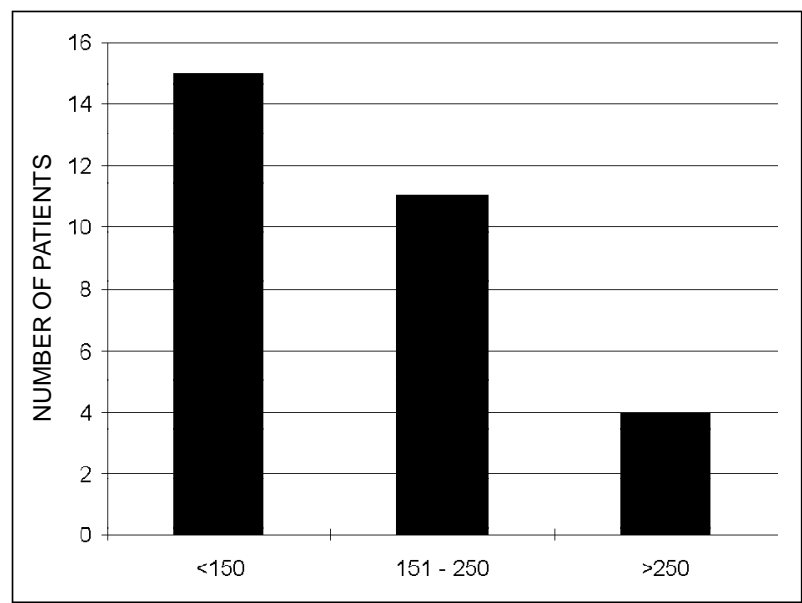

Fig. 3 - Pulmonary vascular resistency. PVR- dyn $/ \mathrm{s} / \mathrm{cm}^{5}$.

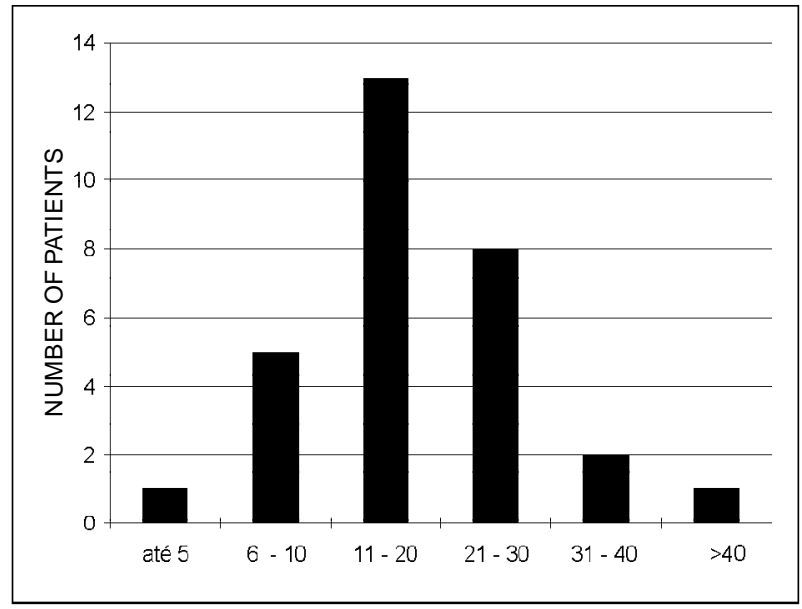

Fig. 4 - Pulmonary shunt. Pulmonary shunt $\%$. 
One patient had an acceptable pulmonary shunt (up to 5\%); in 5 patients it ranged from 6 to $10 \%$; in 11 patients from 11 to $20 \%$; in 8 patients from 21 to $30 \%$; in 2 patients from 31 to $40 \%$; and in 1 patient $>40 \%$ (fig. 4 ).

The mean value for $\mathrm{DO}_{2}$ was $656.07 \pm 231.9 \mathrm{~mL} / \mathrm{min} / \mathrm{m}^{2}$ and for $\mathrm{VO}_{2}$ was $282.52 \pm 139.43 \mathrm{~mL} / \mathrm{min} / \mathrm{m}^{2}$. There was no correlation between $\mathrm{DO}_{2}$ and $\mathrm{VO}_{2}(\mathrm{p}=0.42)$ (fig. 5). There was also no correlation between CVP and PCWP ( $\mathrm{p}=0.065$ ) (fig. 6).

The vasoactive drugs used according to data obtained during monitoring are listed in table II.

Dobutamine was used in one patient; dopamine in 4; association of dobutamine and dopamine in 10 patients; association of dobutamine, dopamine and norepinephrine in 9 patients; association of dopamine and norepinephrine in 4; association of dobutamine, dopamine and sodium nitroprusside in 2; and association of dobutamine and sodium nitroprusside in one patient.

Five patients had CI $<2 \mathrm{~L} / \mathrm{min} / \mathrm{m}^{2}$ and required circulatory support. Table III shows the values for CI and SVR,

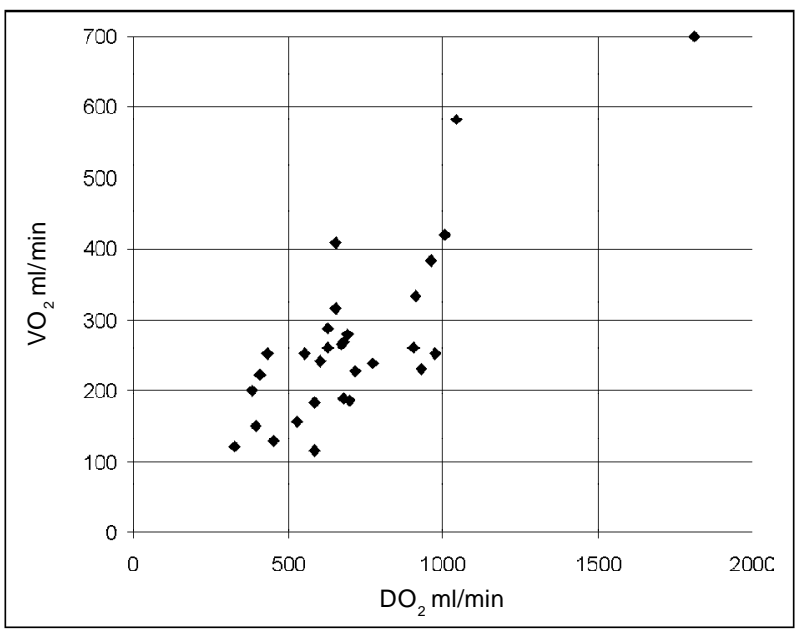

Fig. 5 - Correlation between $\mathrm{DO}_{2}$ and $\mathrm{VO}_{2}(\mathrm{ml} / \mathrm{min})$. There was no significant correlation between $\mathrm{DO}_{2}$ and $\mathrm{VO}_{2}(\mathrm{p}=0.42)$.

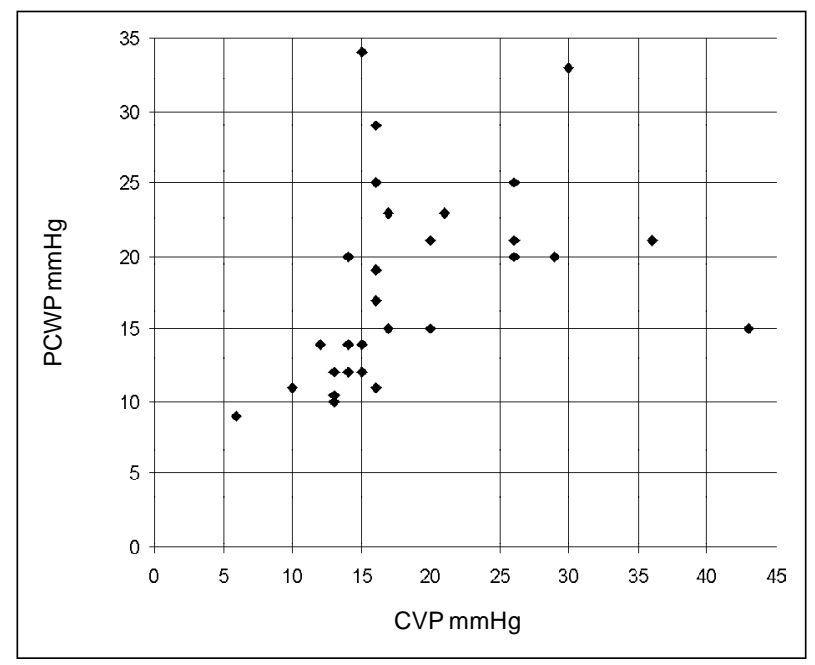

Fig. 6 - Correlation between central venous pressure (CVP) and pulmonary capillary wedge pressure (PCWP). There was no significant correlation between PVC and PCWP $(\mathrm{p}=0.065)$.

\begin{tabular}{|lc|}
\hline \multicolumn{2}{|c|}{ Table II - Vasoactive drugs used } \\
\hline & Number of patients \\
\hline Dobutamine & 1 \\
Dopamine & 4 \\
Dopamine + dobutamine & 10 \\
Dopamine + dobutamine + noradrenaline & 9 \\
Dopamine + noradrenaline & 4 \\
Dobutamine + dopamine + nitroprusside & 2 \\
Dobutamine + nitropusside & 1 \\
Total & 30 \\
\hline
\end{tabular}

\begin{tabular}{|c|c|c|c|c|}
\hline \multicolumn{5}{|c|}{ Table III - Patients with cardiac index $<2.0 \mathrm{~L} / \mathrm{min} / \mathrm{m}^{2}$} \\
\hline & CI/SVR & Circulatory support & Drugs & Outcome \\
\hline 1 & $1.9 / 1369$ & IAB & $\mathrm{Db}, \mathrm{D}, \mathrm{SN}$ & - \\
\hline 2 & $1.6 / 1134$ & Bleeding & $\mathrm{Db}, \mathrm{D}$ & - \\
\hline 3 & $1.6 / 1653$ & $\mathrm{IAB}+\mathrm{CP}$ & $\mathrm{Db}, \mathrm{D}, \mathrm{SN}$ & + \\
\hline 4 & $1.8 / 1140$ & $\begin{array}{l}\text { Leriche's } \\
\text { Syndrome }\end{array}$ & $\mathrm{Db}, \mathrm{D}$ & - \\
\hline 5 & $1,35 / 2425$ & - & $\mathrm{Db}, \mathrm{SN}$ & + \\
\hline \multicolumn{5}{|c|}{$\begin{array}{l}\text { CI/SVR- cardiac index / systemic vascular resistance; Db- dobutamine; D- } \\
\text { dopamine; SN- sodium nitroprusside; +: good outcome; -: death; IAB: } \\
\text { intraaortic balloon; } \mathrm{CP} \text { : centrifuge pump. }\end{array}$} \\
\hline
\end{tabular}

drugs used, type of circulatory support and outcome of each patient. Mechanical circulatory support was used in only 2 patients.

One patient had significant bleeding, another had Leriche's syndrome, and another patient improved after using vasoactive drugs. In these cases, therefore, circulatory support was not employed.

There were no complications deriving from the use of the SGC.

Among the monitored patients, 16 died and 14 had a good outcome.

All patients without initial hemodynamic stability, who did not use the SGC, did not die. In the whole group, the mortality rate was $5.25 \%$. Of all patients with hemodynamic instability monitored with the SGC, 3 had preoperative ejection fraction (EF) $<40 \%$ and 2 died; from the 7 patients with $E F$ between $40 \%$ and $55 \%, 5$ died; from the 20 patients with $\mathrm{EF}>55 \%, 9$ died. Among the 16 patients who died, 2 had coronary heart disease in 2 arteries, 5 patients in 3 arteries, and 3 patients had coronary heart disease asso-ciated with valvular heart disease. From the patients with valvular heart disease who died, 4 had single-valve disease and one patient had a double-valve disease. One patient with cardiomyoplasty evolved with severe systemic inflammatory response syndrome (SIRS) in the POP and died. Seven patients who died had chronic obstructive pulmonary disease, 4 had diabetes mellitus and 2 had chronic renal failure.

\section{Discussion}

Invasive hemodynamic monitoring with the SGC has a broad use in situations of hemodynamic instability in critically ill patients. 
In the United States, around 1 million catheters are used per year for hemodynamic monitoring at a cost of 2 billion dollars ${ }^{3}$.

Gore et $\mathrm{al}^{4}$, in a study published in 1987 on the use of SGC in patients with complicated AMI, observed a higher mortality in the group monitored with the SGC as compared with the group monitored with the CVC. That study was neither prospective nor randomized, allowing us to assume that the patients monitored with the SGC were in a more critical condition. After that study, many others were published in the search for the answer to the question: is it worth spending so much money on a monitoring procedure that does not increase the patient's survival? ${ }^{5-8}$

We retrospectively evaluated 30 patients who had undergone cardiac surgery. These patients had hemodynamic instability in the early POP and underwent invasive hemodynamic monitoring with SGC. Our study showed that in the POP of cardiac surgery, most of the patients had hemodynamic instability resulting from mixed or hyperdynamic shock due to SIRS.

Measurements obtained by hemodynamic monitoring defined our therapeutical management and, in 13 patients, norepinephrine was used to enhance the vascular tonus. Sodium nitroprusside was used in only 3 patients (table II).

Another point to be stressed is that we did not find the correlation between CVP and PCWP. It is known that the control of the blood volume based only in the measurement of CVP is not safe.

Hemodynamic monitoring also guided us in the indication for mechanical circulatory support in patients with $\mathrm{CI}<2 \mathrm{~L} / \mathrm{min} / \mathrm{m}^{2}$. Circulatory support with the centrifuge pump associated with the intraaortic balloon was used in one patient and, in another patient, only the intraaortic balloon was used.

Davies et $\mathrm{al}^{9}$ also concluded that monitoring with the SGC was useful for orienting the control of the blood volume, the use of vasoactive drugs and even the choice of the anesthesia employed in 220 surgical patients.

We found no correlation between $\mathrm{DO}_{2}$ and $\mathrm{VO}_{2}$, as previously observed by Routse et $\mathrm{al}^{10}$.

As the hemodynamic monitoring with the SGC is a very invasive and expensive method, less invasive and expensive methods are currently being investigated.

Transesophageal Doppler echocardiography might be a solution to this problem; however, the values obtained with this method vary greatly when compared with those obtained with the SGC ${ }^{11}$.

Thoracic bioimpedance has similar limitations. Thomas et al ${ }^{12}$ compared cardiac output (CO) measurement with bioimpedance and SGC in 28 patients after myocardial revascularization. In intubated patients, bioimpedance showed up to $30 \%$ smaller values than those obtained with the SGC.

Monitoring with the SGChas its risks and complications. In our study, however, the patients monitored with the SGC showed no complications related to the use of the catheter.

Nishikawa et al $^{13}$ divided the complications into two groups: those caused by the venous puncture and those due to the SGC. Pneumothorax had an incidence of $1 \%$ to $6 \%$ and arrhythmias of $30 \%$ to $60 \%$. In the 1970 s, pulmonary infar-ction had an incidence of up to $7.2 \%$; after the use of intra-flow, however, the risk was practically abolished.

The incidence of thrombosis inside the cardiac chambers, where the catheter passes, was $30 \%$, in the postmortem studies. Rupture of the pulmonary artery occurred in $0.1 \%$ to $0.2 \%$ and sepsis in $1 \%$ of the patients.

During the measurement of the $\mathrm{CO}$, several errors can occur due to temperature, injected volume, time of injection, administration of fluids, hypotension, slow flow, incorrectly positioned catheter, shunts and other problems.

Wallace et al ${ }^{14}$ found great differences in the values of $\mathrm{CO}$ measured with the use of saline solution at room temperature, when compared with the values obtained using a cold saline solution.

In 1989, Tuman et al ${ }^{15}$ assessed morbidity and mortality in 1,094 patients with complicated AMI, comparing monitoring with CVC and SGC and found no difference. Zion et al ${ }^{16}$ compared both modalities of monitoring in 371 patients and observed a higher mortality in patients with severe ventricular failure monitored with SGC. Out of our 30 patients monitored with the SGC, 16 died and 14 survived.

From the patients who died, 9 had a normal EF in the preoperative period. They developed hemodynamic instability due to SIRS or mixed shock, which led to multiorgan failure and death. Patients with triple coronary heart disease or association of coronary heart disease with valvular heart disease were at a higher risk. With regard to previous diseases, chronic obstructive pulmonary disease (COPD) had the highest risk and almost half of the patients (7) who died, had COPD associated with cardiac disease.

Pearson et al $^{8}$ evaluated the cost/benefit ratio of three modalities of monitoring after cardiac surgery, in 226 patients: CVC, SGC, and SGC plus continuous venous saturation. This randomized study showed a much higher cost in patients monitored with the SGC, with no differences in mortality; however, patients monitored with CVC and with higher instability were randomized again for the two other modalities of monitoring. At the end of the research, only 28 patients out of 226 were monitored with the CVC.

In the review by Matthay et $\mathrm{al}^{5}$, the success rate of the values of the PCWP and $\mathrm{CO}$, through the clinical evaluation of intensive care unit patients, did not reach $50 \%$. This confirmed our opinion that in cases of cardiac surgery with hemodynamic instability, it is impossible to manage the patient without invasive monitoring, which defines the type of hemodynamic alteration and the appropriate vasoactive drugs to be used.

The Ontario group organized a prospective and randomized study ${ }^{17}$ comparing monitoring with the SGC and CVC, but they could only gather 33 patients, because the physicians refused to leave the critically ill patients without invasive monitoring due to ethical reasons. Guyatt et al ${ }^{17}$ published the results obtained in these 33 patients showing the same mortality with the two modalities of monitoring.

Discussion about the use of the SGC called so much 
attention to the intensivists, that the journal Chest published a series of letters with the title: "Defenders of the pulmonary artery catheter" ${ }^{18}$.

The consensus statement about the use of the SGC in cardiac surgery published by the journal Critical Care Medicine, in $1997^{19}$, defined that invasive hemodynamic monitoring with SGC could be useful in patients undergoing high-risk car-diac surgery, with impairment in ventricular function, con-cluding that there were no scientific bases to justify the temporary suspension of the use of the SGC. The discus-sion, however, continues ${ }^{20,21}$.

We conclude that hemodynamic monitoring with the SGC is fundamental in patients undergoing cardiac surgery, who have hemodynamic instability in the POP. The value of PCWP is important to assess the blood volume of the patient; measurement of SVR is fundamental for the choice of vasoactive drugs, and the $\mathrm{CI}$ is fundamental in the indication for circulatory support.

\section{References}

1. Dexter BL, Haynes FW, Burwel CS, Eppinger EC, Seibel RE, Evans JM. Studies of congenital heart disease I: Technique of venous cateterization as a diagnostic procedure. J Clin Invest 1947; 26: 547-53.

2. Swan HJC, Ganz W, Forrester J, Marcus H, Diamond G, Chonete D. Catheterisation of the heart in man with use of the a flow-directed bolloon-tipped catheter. N Engl J Med 1970; 283: 447-51.

3. Dalen JE, Bone RC. Is it time to pull the pulmonary artery catheter? JAMA, 1996; 18: 916-18.

4. Gore JM, Goldberg RJ, Spodick DH, Alpert JS, Dalen JE. A community wide assessment of the use of pulmonary artery catheters in pacients with acute myocardial infarction. Chest 1987; 92: 721-7.

5. Matthay MA, Chatterjeek K. Bedside catheterisation on of the pulmonary artery: Risks compared with benefits. Ann Int Med 1988; 109: 826-34.

6. Cernaianu AC, Moore MW, Posner MA. Invasive monitoring of cardiac surgical patient. Anesth Analg 1990; 70: 671-3.

7. Chung RS, Magilligan D, Eisiminger RR, Fried MA, Serwatowski JA, Gerdeman KS. Prediction of post-cardiopulmonary bypass cardiac output. Ann Thorac Surg 1989; 47: 297-9.

8. Pearson KS, Gomez MN, Moyers JR, Carter JG, Tinker JH. A cost/benefit analisis of randomized invasive monitoring patients undergoing cardiac surgery. Anesth Analg 1989; 69: 336-41.

9. Davies MJ, Cronin HD, Domaingue CM. Pulmonary artery catheterization. An assessment of risks and benefits in 220 surgical patients. Anaesth Intensive Care 1982; 10: 9-14

10. Routsi C, Vincent JL, Bakker J, et al. Relation between oxygen consumption and oxigen delivery in patients after cardiac surgery. Anesth Analg 1993; 77: 1104-10.
11. Jardin F, Valtier R, Beauchet A, Dubourg O, Bourdarias JP. Invasive monitoring combined with two-dimensional echocardiographic study in septic shock.Intensive Care Med 1994; 20: 550-4.

12. Thomas NA, Ryan J, Doran BRH, Polard BJ. Bioimpendance versus thermodilution cardiac output measurement: the Bomed NCCOM3 after coronary bypass surgery. Intensive Care Med 1991; 17: 383-6.

13. Nishikawa T, Dohi S. Errors in the measurement of cardiac output by ther-modilution. Can J Anaesth 1993; 40: 142-53.

14. Wallace DC, Winslow EH. Measurement of cardiac output.Effects of iced and room temperature injectate on cardiac output measurements in critically ill patients with low and high cardiac outputs. Heart Lung 1993; 22: 55-63.

15. Tuman KJ, Mc Carthy RJ, Spiess BD, et al. Effect of pulmonary artey catheterisation on autcome in patients undergoing coronary artery surgery.Anesthesiology 1989; 70: 199-206.

16. Zion MM, Balkin J, Rosenmann D, SPRINT study group. Use of pulmonary artery catheters in patients with acute myocardial infarction. Analysis of experience in 5841 patients in the SPRINT registry. Chest 1990; 98: 1331-5.

17. Guyatt $G$ and Ontario Intensive Care Study Group. A randomized control trial of the right heart catheterisation in criticaly ill pacients. J Intensive Care Med 1991; 6: 91-5.

18. Robin E. Defenders of the pulmonary artery catheter. Chest 1988; 93: 1059-66.

19. Pulmonary Artery Catheter Conferance Participants. Pulmonary artery catheter consensus conference:consensus statement. Crit Care Med 1997; 25: 910-24.

20. Sibbald WJ, Sprung CL. The pulmonary artery catheter. The debate continues. Chest 1988; 94: 899-901.

21. Shak K, Sami H, Rao TLK. Cost of invasive monitoring; A yet unresolved issue. Anesth Analg 1990; 70: 463-4 